\title{
Die Voorkoms en Aard van Gehoorprobleme en Middeloorpatologieë by 'n Groep Swart Stedelike Kinders in Graad I
}

\author{
Mirna Nel, B Log (Pretoria)* \\ Willem Odendaal, MB ChB M Med (ORL) (Pretoria) \\ Marina Hurter, B Log (Pretoria)* \\ Santie Meyer, M Log (Pretoria)* \\ Anita van der Merwe, DPhil (Pretoria)* \\ *Departement Spraakheelkunde en Oudiologie, \\ Universiteit van Pretoria \\ Departement Oor-, Neus- en Keelheelkunde, \\ Universiteit van Pretoria
}

\section{OPSOMMING}

Die doel van die studie was om die aard en prevalensie van middeloordisfunksie by graad I stedelike swart kinders te bepaal. 146 kinders uit.' $n$ primêre skool het 'n oor-, 'neus- en keelondersoek, suiwertoon-en immittansiemetings ondergaan. 92,8\% van die ore was beide otologies en oudiologies normaal. Die prevalensie van middeloorpatologie was 7,2\%. Die algemeenste middeloorpatologie was sereuse otitis media. Uit die 292 ore het 18 ore met sereuse otitis media, 2 met 'n retraksie van die timpaniese membraan en slegs 1 met 'n perforasie voorgekom.

\section{ABSTRACT}

The aim of the study was to determine the type and the prevalence of middle ear dysfunction in grade 1 urban black children. 146 children attending a primary school received an ear, nose and throat examination as well as pure tone and immittance screening. $92,8 \%$ of these ears were otologically and audiologically normal. The prevalence of middle ear pathology was $7,2 \%$. Serious otitis media was the most common middle ear pathology (18 out of 292 ears tested). Only 2 retracted tympanic membranes and one perforation were noted.

Middeloorpatologie, en meer spesifiek otitis media, is ' $n$ kindersiekte met 'n baie hoë voorkoms, veral by kinders van ses jaar en jonger (M'Shane \& Mitchell, 1979). Otitis media toon ' $n$ hoë voorkoms in gebiede waar mediese sorg ontoereikend is en die populasie onbewus is van die implikasies van die toestand (Northern \& Downs, 1984).

Wilson (1985) sê dan ook dat otitis media 'n hoë voorkoms het in gebiede waar daar, baie infeksies, ondervoeding en swak higiëne voorkom. In hierdie verband het verskeie oorsese studies al getoon dat in lae sosio-ekonomiese bevolkings 'n hoë voorkoms van middeloorpatologieë voorkom, en die bevolkingsgroepe sodoende hoërisikogroepe vir die siekte is (Corth \& Harris, 1984; Northern, 1978; Wilson, 1985).

Indien otitis media chronies voorkom, veroorsaak dit 'n gehoorverlies, maar kan ook sekondêre probleme veroorsaak, naamlik vertraagde taalontwikkeling /Holm \& Kunze, 1969), ouditiewe perseptuele probleme (Holm \& Kunze, 1969|, verminderde intellektuele vermoëns (Downs, 1977), swak akademiese prestasies (Gottlieb, 1979; Kaplan, 1973) en gedrags- en emosionele probleme (Gottlieb, 1979]. Bess (1985) sê dat "More than thirty studies covering approximately 3500 children have agreed that a relationship exists betweèn early fluctuating hearing loss and later decreased learning skills." (p.44.)
Die rede vir bogenoemde sekondêre probleme kan waarskynlik toegeskryf word aan periodes van ouditiewe deprivasie wat veroorsaak word deur chroniese of herhaalde episodes van otitis media in die vroeë kinderjare. "Deprivation would seem to have at least two impacts: the retardation of language and learning potential and the direct effect on the auditory system itself." (Glorig en Gerwin, 1974, p.5.)

Uit die voorafgaande bespreking is dit dus baie duidelik dat otitis media so vroeg as moontlik opgespoor en behandel moet word ten einde die negatiewe sekondêre gevolge te verhoed. Dit is derhalwe belangrik dat hoërisikopopulasies geïdentifiseer moet word, sodat konserveringsmaatreëls getref kan word. Die lae sosio-ekonomiese toestande van ' $n$ groot deel van die swart stedelike bevolking in Suid-Afrika maak van hulle ook 'n hoërisikobevolking. Hulle het 'n hoë populasiegroei, swak behuising en ontspanningsgeriewe, 'n lae algemene gesondheidstoestand en 'n lae inkomste (Morris, 1980). Alhoewel daar nie 'n sosio-ekonomiese opname vir Mamelodi beskikbaar is nie, word die gemiddelde sosioekonomiese omstandighede van die gebied ook as laag in vergelyking met ander rassegroepe in die omgewing gesien. Die indikatore waarvolgens dit beoordeel word, is inkomste, opvoedkundige standaard en gesondheidstatus. Werkloosheid, onstabiele gesinslewe en oorbehuising kom ook voor (Morris, 1980; Van der Walt, 1987). 
Min inligting is tot dusver bekend ten opsigte van die voorkoms van middeloorpatologie by swart stedelike kinders in S.A. (Voogt, Halama \& Van der Merwe, 1986).

\section{EKSPERIMENT}

\section{Proefpersone}

'n Primêre skool vir normaalhorende swart kinders is deur middel van 'n eenvoudige ewekansige steekproef geselekteer van die primêre skole in Mamelodi, naby Pretoria. Al die graad I kinders in die skool is in die eksperiment gebruik.

Tabel 1: Voorstelling van relevante gegewens omtrent die proefpersone

\begin{tabular}{|c|r|r|r|}
\hline $\begin{array}{c}\text { OUDERDOM } \\
\text { IN JARE }\end{array}$ & MANLIK & VROULIK & TOTAAL \\
\hline 5 & 1 & 2 & 3 \\
6 & 40 & 40 & 80 \\
7 & 27 & 18 & 45 \\
8 & 5 & 4 & 9 \\
9 & 4 & 2 & 6 \\
10 & 2 & 1 & 3 \\
\hline TOTAAL & 79 & 67 & 146 \\
\hline
\end{tabular}

\section{Apparaat}

Die apparaat wat vir die oor-neus-en-keelondersoek gebruik is, is standaardapparaat, naamlik 'n koplig, neusspekulum en otoskoop.

'n Draagbare siftingsimmittansiemeter, die Grason Stadler, INC GSI 28A, is vir die immittansiesiftingsmetings gebruik, Die meter is geyk volgens ISO 1975 standaarde.

Die apparaat vir die siftingsuiwertoonondersoek was 'n Madsen Electronics OB40 draagbare oudiometer. Dieloudiometer is volgens SABS 0154-1983 aangepas en volgens 1986 standaarde geyk.

Toetsing is in 'n stil vertrek, weg van die klaskamer- en speelgrondlawaai, uitgevoer.

\section{Prosedure}

Die studie is in die vroeë herfs uitgevoer voordat die voorkoms van boonste lugweginfeksies en gepaardgaande middeloorpatologie in voorkoms toeneem.

Elke kind het 'n oor-neus-en-keelondersoek ondergaan deur 'n oor-, neus- en keelarts van die Departement Oor-, Neusen Keelheelkunde, aan die Universiteit van Pretoria. Oormatige oorwas is verwyder sodat immittansiemetings suksesvol uitgevoer kon word. Die otoskopiese bevindinge is aangeteken.

Siftingsimmittansiemetings is daarna uitgevoer. Hierdie metings sluit timpanometrie, meting van statiese akoestiese immittansie en akoestiese refleksmetings in (Northern en Downs, 1984; Bess en McConnell, 1981). Die akoestiese refleksmetings is ipsilateraal, by ' $\mathrm{n} 1000 \mathrm{~Hz}$ en $105 \mathrm{~dB}$ gedoen (Northern en Downs, 1984).

Daarna het die suiwertoonsiftingstoets gevolg. Gehoorsif- ting is gedoen by $500 \mathrm{~Hz}, 1000 \mathrm{~Hz}, 2000 \mathrm{~Hz}$ en $4000 \mathrm{~Hz}$ 陟 thern en Downs, 1984). ' $n$ Onderwyseres is gebruik om die kinders te help kondisioneer vir toetsing en ook om as tolk op te tree.

\section{Analise van die data}

Gehoorsensitiwiteit soos bepaal met suiwertoonsiftingtoetsing is as normaal beskou indien die proefpersoon response gelewer het by $500 \mathrm{~Hz}, 1 \mathrm{kHz}$, by $20 \mathrm{~dB}$ GP en $25 \mathrm{~dB}$ GP by $4 \mathrm{kHz}$ volgens ASHA riglyne laangehaal in Northern en Downs, 1984).

In die geval ván immittansiemetings behaal die persoon normale siftingsresultate as ' $n$ tipe A-timpanogram, met ' $n$ piek tussen $+100 \mathrm{mmH} \mathrm{O}$ en $100 \mathrm{mmH} \mathrm{O}$, opgeteken word en 'n akoestiese refleks by $105 \mathrm{~dB}$ GP of laer by $1000 \mathrm{~Hz}$ ontlok word (ASHA riglyne, aangehaal in Northern en Downs, 1984; Bess en McConnell, 1981). 'n Proefpersoon behaal af wykende siftingsresultate indien die refleks afwesig is selfs in die teenwoordigheid van ' $n$ tipe A-timpanogram en/of ' $n$ tipe As-, Ad-, B- of C-timpanogram verkry word (Jerger, 1970).

\section{RESULTATE EN BESPREKING}

Tabel 2: Suiwertoon- en immittansiesiftingstoetsresultate

\begin{tabular}{|c|c|c|c|}
\hline & OUDIOMETRIESE RESULTATE & $\begin{array}{c}\text { AANTAL } \\
\text { KINDERS } \\
\mathrm{N}=146\end{array}$ & $\%$ \\
\hline 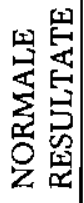 & $\begin{array}{l}\text { Normale suiwertoon- en immit- } \\
\text { tansieresultate }\end{array}$ & 106 & 72,6 \\
\hline \multirow{3}{*}{ 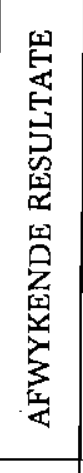 } & $\begin{array}{l}\text { Afwykende suiwertoon- en nor- } \\
\text { male immittansieresultate, d.w.s. } \\
\text { sensories neurale betrokkenheid }\end{array}$ & 0 & \multirow{2}{*}{$\begin{array}{c}0 \\
25,3\end{array}$} \\
\hline & $\begin{array}{l}\text { Normale suiwertoonresultate } \\
\text { maar afwykende immittansiere- } \\
\text { sultate, d.w.s. middeloordisfunk- } \\
\text { sie sonder 'n gehoorverlies }\end{array}$ & 37 & \\
\hline & $\begin{array}{l}\text { Afwykende suiwertoon- en immit- } \\
\text { tansieresultate, d.w.s. geringe ge- } \\
\text { hoorverlies met 'n middeloordis- } \\
\text { funksie }\end{array}$ & 3 & 2,1 \\
\hline & SUBTOTAAL & 40 & 27,4 \\
\hline
\end{tabular}

In tabel 2 word die oudiometriese siftingstoetsresultate vir die 146 kinders uiteengesit.

Uit tabel 2 blyk dit duidelik dat $72,6 \%$ van die kinders normale resultate in die oudiometriese siftingsondersoeke behaal het.

Hierdie betreklike hoë slaagsyfer is teen die verwagting in, omdat ander studies wat ook op lae sosio-ekonomiese populasies uitgevoer is, se normale resultate dikwels laer as $72,6 \%$ is, byvoorbeeld by die Indo-Chinese vlugtelingkin. ders is die slaagsyfer vir siftingsgehoortoetse $31,2 \%$ (Corth \& Harris, 1984) en by 'n spesifieke groep Venda plattelandse kinders in die Dzanani distrik (Oosthuizen, 1986) 48,3\%. 
Daarenteen is daar ander studies van lae sosio-ekonomiese populasies in suidelike Afrika wat ook 'n hoë persentasie normale resultate vertoon, byvoorbeeld 'n groep plattelandVenda kinders van Tshikunda-Malema 78\% (Meyer en Van den Berg, 1985) en by graad I Kleurlingkinders, van Eersterus buite Pretoria, 86,4\% (Meyer, Hurter \& Van Rensburg, 1987). Die $72,6 \%$ normale resultate van die swart stedelike bevolking, vergelyk dus goed met laasgenoemde twee studies, wat albei ook in suidelike Afrika gedoen is.

Uit tabel 21 blyk dit duidelik dat $27,4 \%$ van die kinders in een of beide ore afwykende oudiometriese resultate vertoon. Daar is geen voorkoms van afwykende suiwertoon, en normale immittansiesiftingsresultate nie, dit wil sê geen sensories neurale betrokkenheid is by die eksperimentele groep gevind nie. Daar is egter 'n voorkoms van $25,3 \%$ wat normale suiwertoonsiftingsresultate, maar afwykende immittansiesiftingsresultate vertoon en wat daarop dui dat ' $n$ moontlike middeloorpatologie teenwoordig is. Slegs $2,1 \%$ van die kinders vertoon afwykende suiwertoon- en afwykende immittansiesiftingsresultate wat waarskynlik dui op gevorderde middeloorpatologie by hierdie kinders.

Die hoër voorkoms van middeloorpatologie teenoor sensories neurale gehoorverlies stem ooreen met vorige navorsing van Harvey en Wilmot (1969). Hulle navorsing dui daarop dat in die skoolgaande populasie, meer as sowat $70 \%$ van alle gehoorprobleme die gevolg is van middeloorpatologie.

Dit is opvallend dat 37 kinders uitvalle toon op slegs immittansiesiftingstoetsresultate, maar die suiwertoonsiftingstoets slaag. Hulle toon dus tekens van middeloorprobleme, sonder dat hulle gehoorsensitiwiteit beduidend verswak het. Hulle mag egter wel gehoorverliese kleiner as $20 \mathrm{~dB}$ GP getoon het indien suiwertoondrempels bepaal is. Dit bevestig Brooks $\{1980\}$ se stelling dat baie kinders met middeloorpatologie se gehoor as normaal beskou sou word indien immittansiemetings nie deel van die toetsbattery sou wees nie.
Altesaam $27,4 \%$ van die kinders vertoon uitvalle op die immittansiemetings. Alhoewel die persentasie hoër is as die $14,9 \%$ van Voogt, et al. (1986) se voorskoolse swart kinders, is die resultate nie direk vergelykbaar nie, aangesien die slaag/faal-kriteria in die 2 studies verskil.

In tabel 3 word die aantal ore sowel as die \% ore ten opsigte van die oudiometriese sowel as die otologiese resultate aangetoon. Vir die diagnose van sereuse otitis media is van Cantekin (1983) se algoritme gebruik gemaak.

Uit tabel 3 blyk dit dat $77,7 \%$ van die ore beide oudiologies en otologies normaal is. Vier en veertig $(15,1 \%)$ van die ore wat egter uitgeval het op die suiwertoon-en immittansiesiftingstoetse is egter ook otologies as normaal bevind sodat $92,8 \%$ van die populasie otologies normaal was. Hieruit volg dat die prevalensie van middeloorpatologie $7,2 \%$ is.

Die tipe middeloorpatologie wat die algemeenste voorkom is sereuse otitis media $(6,2 \%)$. Slegs 1 perforasie het voorgekom.

Uit ander navorsing in verband met sereuse otitis media en perforasies blyk die volgende: Die voorkoms van slegs perforasies onder Navajo skobolkinders was $14 \%$, Eskimo kinders $32 \%$, Alaskaanse kinders $17 \%$, Amerikaans-Indiaanse kinders $6,5 \%$ en Soshanguve kleuters 1,6\% (Northern, 1978; Voogt, et al. 1986; Howie, 1977; Johnson en Watrous, 1978). Die voorkoms by die getoetse Mamelodi kinders was slegs $0,3 \%$. Die voorkoms van sereuse otitis media by die Mamelodi kinders $(6,2 \%)$ is ook heelwat laer as in ander kinderpopulasies (Johnson \& Watrous, 1978).

Oor die algemeen kan dus gesê word dat daar nie in hierdie populasie kinders ' $n$ hoë voorkoms van middeloorpatologie voorkom nie. Die studie se resultate vergelyk redelik goed met die $3,6 \%$ otitis media soos verkry by 'n plattelandse Venda kinderpopulasie (Halama, Voogt \& Musgrave, 1986).

Tabel 3: Die otologiese diagnose in vergelyking met die oudiometriese siftingsresultate

\begin{tabular}{|c|c|c|c|c|c|c|}
\hline \multirow{3}{*}{$\begin{array}{l}\text { IMMITTANSIE EN SUIWERTOONRESULTATE } \\
\text { TIPES }\end{array}$} & \multicolumn{6}{|c|}{ DIAGNOSE VAN MIDDELOORTOESTAND } \\
\hline & \multirow[t]{2}{*}{ NORMAAL } & \multicolumn{5}{|c|}{ AFWYKĒND } \\
\hline & & RETRAKSIE & $\begin{array}{l}\text { SEREUSE } \\
\text { OTITIS } \\
\text { MEDIA }\end{array}$ & $\begin{array}{l}\text { CHRONIESE } \\
\text { OTITIS } \\
\text { MEDIA: } \\
\text { PERFORASIE }\end{array}$ & $\begin{array}{l}\text { TOTAAL } \\
\mathrm{N}=292\end{array}$ & $\%$ \\
\hline $\begin{array}{l}\text { Tipe A-timpanogram, teenwoordige akoestiese } \\
\text { reflekse, normale suiwertoonresultate }\end{array}$ & 227 & 0 & 0 & 0 & 227 & 77,7 \\
\hline $\begin{array}{l}\text { Tipe A-timpanogram met afwesige akoestiese } \\
\text { reflekse, maar normale suiwertoonresultate }\end{array}$ & 15 & 0 & 0 & 0 & 15 & 5,1 \\
\hline $\begin{array}{l}\text { Tipe B-timpanogram met afwesige akoestiese } \\
\text { reflekse, maar normale suiwertoonresultate }\end{array}$ & 0 & 0 & 15 & 1 & 16 & 5,5 \\
\hline $\begin{array}{l}\text { Tipe B-timpanogram met afwesige akoestiese } \\
\text { reflekse en geringe konduktiewe verlies }\end{array}$ & 0 & 0 & 3 & 0 & 3 & 1,0 \\
\hline $\begin{array}{l}\text { Tipe C-timpanogram met afwesige akoestiese } \\
\text { reflekse en normale suiwertoonresultate }\end{array}$ & 19 & 0 & 0 & 0 & 19 & 6,5 \\
\hline $\begin{array}{l}\text { Tipe C-timpanogram met afwesige akoestiese } \\
\text { reflekse en normale suiwertoonresultate }\end{array}$ & 10 & 2 & 0 & 0 & 12 & 4,1 \\
\hline TOTAAL & 271 & 2 & 18 & 1 & 292 & 22,3 \\
\hline$\%$ & 92,8 & & 7,2 & & & 100 \\
\hline
\end{tabular}


Alhoewel die voorkoms van middeloorpatologie sekerlik ideaal gesproke kan verlaag, is die groep kinders in die lae sosio-ekonomiese omgewing nie 'n hoërisikogroep vir middeloorpatologie nie.

Wanneer die otologiese diagnose en die oudiometriese siftingsresultate vergelyk word, blyk die volgende:

Daar is swak ooreenstemming wanneer al die oudiometriese resultate normaal is, maar die akoestiese reflekse afwesig is. Die teenwoordigheid van die akoestiese refleks as siftingskriterium [ASHA in Northern \& Downs, 1984) word dus bevraagteken.

Swak ooreenstemming word ook verkry wanneer tipe C-timpanogramme veroorsaak dat die proefpersoon op die oudiometriese siftingstoets uitval. Die ore word hoofsaaklik otologies as normaal verklaar.

Slegs twee ore, met 'n tipe C-timpanogram gee aanduidings van otoskopies waarneembare middeloorpatologie. Hulle toon ' $n$ retraksie van die timpaniese membraan weens 'n groter negatiewe middeloordruk as $-200 \mathrm{~mm} \mathrm{H} 20$. Die ander 29 ore met tipe C-timpanogramme se negatiewe middeloordruk is minder as $-200 \mathrm{~mm} \mathrm{H20}$, daarom is dit nog nie otoskopies as middeloorpatologieë gediagnoseer nie. Volgens Orchik, Dunn en McNutt (1978), verteenwoordig die ontwikkeling van negatiewe druk, in die middeloorruimte, 'n tussenfase in die ontwikkeling van sereuse otitis media. Dit is dus belangrik dat hierdie kinders verder verwys word vir opvolgtoetsing sodat middeloorpatologieë geïdentifiseer kan word indien die negatiewe middeloordruk nie opklaar nie.

Goeie ooreenstemming tussen die oudiologiese siftingsresuitate en die otologiese diagnose is verkry in die geval van die tipe B-timpanogramme waar al die ore waarneembare middeloorpatologie soos sereuse otitis media of 'n perforasie vertoon het.

\section{GEVOLGTREKKINGS}

Die prevalensie van slegs $7,2 \%$ middeloorpatologie by die groep graad 1 leerlinge was onverwags. Die kinders is in lae sosio-ekonomiese omstandighede wat hulle teoreties 'n hoërisikopopulasie maak. Die prevalensie van $7,2 \%$ is egter heelwat laer as ander verklaarde hoërisikopopulasies [Corth \& Harris, 1984; Northern, 1978).

Die oudiometriese suiwertoonsiftingsresultate toon aan dat geen kinders sensories neurale gehoorverliese vertoon nie, terwyl slegs $2,1 \%$ van die populasie 'n geringe konduktiewe gehoorverlies vertoon.

Die meeste kinders $(25,3 \%)$ wat op die oudiometriese siftingstoetse uitval, vertoon slegs 'n middeloordisfunksie sonder dat hul gehoorsensitiwiteit beduidend beïnvloed word.

Met betrekking tot die tipes patologieë kan die volgende gevolgtrekking gemaak word:

Dit is opvallend dat die middeloorpatologie wat die meeste voorkom, sereuse otitis media is. Al dié ore vertoon dan ook 'n tipe B-timpanogram met afwesige akoestiese reflekse en normale of afwykende suiwertoonsiftingsresultate. Die voorkoms van sereuse otitis media is heelwat laer as die $20,5 \%$ van die Amerikaans-Indiaanse kinders (Johnson en Watrous, 1978). In dié studie is slegs een perforasie. Onder Navajo skoolkinders was daar byvoorbeeld ' $n$ voorkoms van $14 \%$ perforasies en by Eskimo kinders $32 \%$ perforasies. Dit blyk dus of die getoetse Mamelodi kinders in terme van perforasies en sereuse otitis media nie as 'n hoërisikopopulasie beskou kan word in vergelyking met ander hoërisikopopulasies nie. Dit is moontlik toe te skryf aan die gematigde klimaat in die Pretoria omgewing in vergelyking met die klimaat waaraan die Indiaanse en Eskimo kinders blootgestel is wat moontlik kan lei tot verhoogde insidensie van boonste-lugweginfeksies en gepaardgaande middeloorpatologie.

Slegs twee ore met retraksie van die timpaniese membraan het tipe C-timpanogramme getoon. Hulle toon retraksie, as gevolg van ' $n$ negatiewe druk laer as $-200 \mathrm{~mm} \mathrm{H} 2 \mathrm{O}$ wat teenwoordig is in die middeloor ruimte. Die ander 29 ore met tipe C-timpanogramme se negatiewe druk is nie laer as $-200 \mathrm{~mm} \mathrm{H} 2 \mathrm{nie}$, en daarom nog nie otoskopies waarneembaar nie.

Daar word aanbeveel dat ' $n$ afwesige akoestiese refleks in die teenwoordigheid van normale immittansiemetings en suiwertoonsiftingsresultate nie as aanduiding van 'n afwyking beskou word nie. In al die gevalle was die ore otologies normaal.

Ten slotte blyk dit dat die groep kinders, ten spyte van 'n lae sosio-ekonomiese omgewing, en die afwesigheid van gereelde oudiologiese sifting, nie 'n kommerwekkende hoë prevalensienvan middeloorpatologie vertoon nie.

\section{VERWYSINGS}

Bess, F.H. The minimally hearing-impaired ${ }^{-}$child. Ear and Hearing, 6, 43-47, 1985 .

Bess, F.H. en McConnell, F.E. Audiology, Education and the Hearing Impaired child. St. Louis: The CV Mosby Company, 1981.

Brooks, D.N. Impedance Screening in Jerger, J. en Northern, J.L. Clinical Impedance Audiometry. Massachusetts: American Electromedics Corporation, 1980.

Cantekin, E.I. Algorithm for diagnosis of otitis media with effusion in Stool, S.E. en Bluestone, C.D. (eds): Studies in Otitis Media, Pittsburg Otitis media research centre, Progress report, 92, 6, 1983.

Corth, S.B. en Harris, R.W. Incidence of middle ear disease in Indochinese refugee school children. Audiology, 23, 27-37,
1984 .

Downs, M. The expanding imperatives of early identification. 'In Bess, F.H. (ed.): Childhood Deafness: Causation, Assessment and Management. New York: Grune en Stratton, 1977, i

Glorig, A. en Gerwin, K. Detection of Hearing Loss and Ear Disease' in Children. Springfield III: Charles, C. Thomas, 1974.

Gottlieb, M.I. Chronic middle ear disease and auditory perceptual deficits. Is there a link? Clinical Pediatrics, 18, 725-732, 1979.

Halama, A.R., Voogt, G.R. en Musgrave, G.M. Prevalence of otitis media in children in a black rural community in Venda (South Afria). International Journal of Pediatric Otorhinolaryngology, 11, 73-77, 1986.

Harvey, R.M. en Wilmot, T.J. The incidence of deafness in childhood. Journal of Laryngology and Otology, 83, 449-456, 1969

Holm, V.A. en Kunze, R.H. The effects of chronic otitis media on language and speech development. Pediatrics, 43, 833-841. 1969.

Howie, V.M. Acute and recurrent acute otitis media. In Jaffe, B.F. (ed.): Hearing Loss in Children. Baltimore: University Park Press, 1977

Jerger, J. Clinical experience with impedance audiometry. Archives of Otolaryngology, 92,311-324, 1970. 
Johnson, J.S, en Watrous. An acoustic impedance screening pro gram with an American population in Harford, E.R., Bess. F.H., Bluestone, C.D. en Klein, J.O. (eds.): Impedance Screening for Middle Ear Disease in Children. New York: Grune en Stratton, 1978.

Kaplan, G.J. Long term effects of otitis media: A ten year cohort study of Alaska-Eskimo children. Pediatrics, 52, 577-585, 1973.

McShane, D. en Mitchell J. Middle ear disease, hearing loss and educational problems of American Indian children. Journal of American Indian Education, 7-11, 1979.

Meyer, S. en Van den Berg, C. Die voorkomsfrekwensie van oor en gehoorpatologie by kinders in die afgesonderde gemeen skap van Tshikunda-Malema. Die Suid-Afrikaanse Tydskrif vir Kommunikasieafwykings, 32, 71-75, 1985.

Meyer, S., Hurter, M. en Van Rensburg, F. Gehoorsiftingsresultate van 'n groep graad een Kleurlingkinders. Suid-Afrikaanse Tydskrif vir Kommunikasieafwyhings, 34, 43-47, 1987.

Morris, P. Soweto. Johannesburg: Perskor, 1980.
Northern, J.L. Impedance screening in special populations - state of the art. In Harford, E.R., Bess, F.H., Bluestone, C.D. en Klein, J.O. (eds.): Impedance Screening for Middle Ear disease in children. New York: Grune en Stratton, 1978.

Northern, J.L. en Downs, M.P. Hearing in Children. Baltimore, Maryland: The Williams en Wilkins Company, 1984.

Oosthuizen, I. Die aard en voorkoms van gehoorpatologieë in laerskole vir normaalhorende Venda kinders. Ongepubliseerde BLogverhandeling, Universiteit van Pretoria, 1986.

Orchik, D.J., Dunn, J.W. en McNutt, L. Tympanometry as a pre dictor of middle ear effusion. Archives of Otolaryngology, 104, 4-6, 1978 .

Van der Walt, T.J. Persoonlike mededeling. Departement Sosiologie, Universiteit van Pretoria, 1987.

Voogt, G.R., Halama, A.R., Van der Merwe, C.A. Immittance Screening in black preschool children attending day-care centres. Audiology, 25, 158-164, 1986

Wilson, J. Deafness in developing countries. Arch. Otolaryngology, $3,5,1985$. 
